\title{
Game Analysis of Product-Service Integration
}

\author{
Heping Zhong \\ School of Management, Xuchang University (China) \\ Hepingz2004@163.com
}

\section{Abstract:}

Purpose: This paper aims at defining the value creation mechanism and income distribution strategies of product-service integration in order to promote product-service integration of a firm.

Design/methodology/approach: This paper conducts researches quantitatively on the coordination mechanism of product-service integration by using game theory, and uses the methods of Shapley value and Equal growth rate to further discuss income distribution strategies of product-service integration.

Findings: Product-service integration increases the total income of a firm and the added value of the income $\delta \pi$ decreases as the unit price demand variation coefficient of products and services $E$ increases, while decreases as the marginal cost of products $\beta_{P}$ increases, decreases as the marginal cost of services $\beta_{S}$ increases. Moreover, the findings suggest that both income distribution strategies of product-service integration based on Shapley value method and Equal growth rate method can make the product department and service department of a firm winwin and realize the Pareto improvement. The choice of what kind of distribution strategy to coordinate the actions between departments depends on the department playing dominant role in the firm. Generally speaking, for a firm at the center of market, when the product department is the main contributor to firm income, the service department will choose the income distribution strategy of product-service integration based on Shapley value method; when the service department is the main contributor to firm income, the service department 
will choose the income distribution strategy of product-service integration based on Equal growth rate method.

Research limitations/implications: This paper makes some strict assumptions such as complete information, risk neutral, linear cost function and so on and the discussion is limited to the simple relationship between product department and service department.

Practical implications: Product-service integration enables a firm to improve its total income. A firm should take appropriate income distribution strategies in order to promote the its product-service integration.

Originality/value: This paper introduces game theory into the research of product-service integration for the first time and it has reached some valuable conclusions, which has opened up a new field of study in the product-service area.

Keywords: game theory, product-service integration, shapley value, servitization

\section{Introduction}

Products and services are the core issues of marketing management. Due to the flourishing and dynamic market environment, a single product can not meet the need of customers. Quite naturally, the concept of combinations of products and services has emerged to cope with these issues. Since the theory of three levels of products has been proposed, the researches of academia and practice show that a tangible product added intangible services will make up an entire product letting customers obtain satisfactory functions. As a result, the relationship between products and services is attracting the attention of more and more scholars.

Vandermerwe and Rada (1988) firstly advanced the concept of servitization, they divided servitization into three stages: single products or services, combinations of products and services, a bundle of products, services, support, knowledge and self-service. Since then, many scholars have been mainly based on the perspective of Product-dominant logic or Service-dominant logic to investigate extensively the issues. Mathieu (2001) proposed an original classification system: from a service supporting the product to a service supporting the client. Baines, Lightfoot, Benedettini and Kay (2009) discussed the motivity of servitization, the methods and rules of the successful implementation of servitization. Han, Kuruzovich and Ravichandran (2013) examined service expansion of IT product companies. Dachs, Biege, Borowiecki, Lay Jäger and Schartinger (2014) found that service output of firms is still small compared to the product output based on the data from the servitisation of European manufacturing and there is a U-shaped relationship between servitisation and firm size. 
In recent years, more and more scholars begin to focus on the issues of product-service integration (Geum, Lee, Kang \& Park, 2011b). Sundin, Lindahl, Rönnbäck, Ölundh and Östlin (2006) believed that product-service integration is an effective strategy to meet varied and rapidly changing customer needs. Johnstone, Dainty and Wilkinson (2009) found a key challenge concerning integrating the product and service parts of the business to ensure consistent delivery of a seamless value offering to customers based on an in-depth case study of an international aerospace original equipment manufacturer. Geum, Lee, Kang \& Park (2011a) suggested a customisation framework for roadmapping product-service integration according to the technological interface involved, and provided practical guidance in its implementation. Park, Geuma and Lee (2012) proposed a taxonomy of integration of products and services in the form of a dichotomy and framework of the product-service integration cube. Parida, Sjödin, Wincent and Kohtamäki (2014) argued that the companies who have transformed into successful product-service providers have developed key capabilities in business model design, partner network management, integrated development process, and service delivery network management based on the data from Swedish and Finnish frontrunner manufacturing companies.

Previous studies on product-service integration focused on how to integrate products and services. Scholars have proposed the concepts, theoretical framework on product-service integration based on case study, but have paid insufficient attention to researches on the interaction between products and services. Obviously, the coordination issues between product departments and service departments in a firm directly affects the successful integration of products and services. However, the existing literatures lack relevant studies on the impact of coordination between product departments and service departments on product-service integration, particularly lacking studies on mathematical models of product-service integration.

As above mentioned, this paper adopts game theory to research quantitatively the coordination mechanisms of product-service integration through the establishment of mathematical models. The important contribution of this paper is to introduce game theory into the research of product-service integration for the first time and has reached some valuable conclusions, which opens up a new field of study in the product-service area.

\section{Basic models}

\subsection{Model assumptions}

Product-service integration means that the product department collaborates with the service department to the utmost, follows customer demand orientation, takes products and services as an entire product to research and develop, design and produce in order to meet the customer needs more effectively, so as to maximize the income of the firm. Supposing one 
firm is made up of one product department and one service department. The product department is responsible for product design and production. The service department is responsible for the design and production of services added to products and selling of products and services (selling also can be regarded as a kind of service, thus it is placed into service department). Thus, product-service integration is characterized by the fact that the product department and the service department make decisions together to maximize the overall interests of the firm. Non-integration of products and services is characterized by the fact that the product department and the service department make decisions respectively to maximize the interests of his own department (because modern firm management usually takes target responsibility system management or internal accounting management of a department). Therefore, the issue on product-service integration can be regarded as the cooperative game problems of the product department and the service department, in this way, we can use game theory to make optimal analysis of them (Song \& Wei, 2013; Zhang, Xu \& Zhang, 2014). In order to analyze conveniently, the following assumptions might be further made:

Assumption 1: Supposing there is only one firm which supplies products and additional services on the products in a segment of market. The firm sells products bundled with services to customers, and customers have to buy these products and services at the same time. This assumption is reasonable, because a firm can segment the entire market into a submarket where there is only one firm supplying products and services required by customers by finding the corresponding segmentation variables according to the characters of customer's (market) demands.

Assumption 2: In order to simplify the analysis, we suppose the firm supply one kind of product and one kind of additional service for customers in a segment of market. It is essentially to take all the products and services as one kind of product and one kind of service added to the product. Of course, the service attached to the product can be provided by service department or through the way of service outsourcing.

Assumption 3: Supposing in a segment of market, market demand function of products and services is $Q=M-E P$, where $Q$ is the demand of products and services, $\mathrm{M}$ is market capacity (namely the maximal demand of products and services), $E$ is the unit price demand change coefficient of products and services, $P$ is the market price of the product and service, and $M>0, E>0, P>0, Q>0$ (Pindyck \& Rubinfeld, 2013). When market equilibrium comes, the 
supply is equal to the demand, so the output of products and services is equal to the market demand $Q$.

Assumption 4: Suppose the cost function of product department as $C_{P}=C_{1}+B_{P} Q$, where $C_{1}$ is the fixed cost of products, $B_{P}$ is the marginal cost of products, and $C_{1}>0, B_{P}>0$ (Pindyck \& Rubinfeld, 2013).

Assumption 5: Supposing the service department is responsible for selling products and services, namely, the product department supplies products to the service department on settlement price $P_{1}$, the service department sells products bundled with services to customers on market price $P$, and $P_{1}>0, P>P_{1}$. This assumption accords with the practice of most firms, in fact, the production department is responsible for the production of products, marketing department (providing additional services to customers) is responsible for the packaging sales of products and services in a firm.

Assumption 6: Due to limited capacity, the service department can only produce service of the quantity $Q_{1}$, according to the market needs, the service gap of the quantity $Q_{2}$ are needed to be solved by buying services provided by an external professional service firm, namely by service outsourcing. Obviously, when market equilibrium comes, the supply is equal to the demand, and $Q_{1}+Q_{2}=Q_{1}$.

Assumption 7: Suppose the cost function of the service department as $C_{2}=C_{2}+B_{S} Q_{1}+P_{2} Q_{2}$, where $C_{2}$ is the fixed cost of the service department, $B_{S}$ is the marginal cost of the service department's producing services, $P_{2} Q_{2}$ is the cost of buying outsourcing services of the quantity $Q_{2}$ on market price $P_{2}$, and $C_{2}>0, B_{S}>0, P_{2}>0, P>P_{2}$ (Pindyck \& Rubinfeld, 2013).

Assumption 8: Suppose the cost function of the outsourcing service firm as $C_{W}=C_{3}+B_{W} Q_{2}$, where $C_{3}$ is the fixed cost of the outsourcing service firm, $B_{W}$ is marginal cost of outsourcing services, and $C_{W}>0, B_{W}=0$ (Pindyck \& Rubinfeld, 2013). 
Assumption 9: Suppose the outsourcing service firm supply services on market price $P_{2}$ which conform to the linear supply function, we might as well suppose as $P_{2}=B_{S}-\gamma Q_{2}$, where $B_{S}$ is the marginal cost of the service department's producing services, $\gamma$ is the unit demand price variation coefficient of the services, $Q_{2}$ is the quantity of outsourcing services, and $\gamma>0$. This assumption is reasonable. The service department chooses service outsourcing only when the cost of buying external services is below the cost of the service department's producing services, i.e. $B_{S} Q_{2}-P_{2} Q_{2} \geq 0$, thus $P_{2} \leq B_{S}$. Because the market supply function is linear, the assumption $P_{2}=B_{S}-\gamma Q_{2}$ is reasonable.

Assumption 10: The information of the product department and the service department is complete. Their risk preference is neutral, and their decision-making is rational.

\subsection{Models}

When there is no product-service integration in a firm, the product department and the service department make decisions independently, standing in the perspective to maximize the interests of his own department to decide input, output and price. Thus, the income functions of the product department and the service department are as follows respectively.

The income of the product department is:

$$
\pi_{P}=P_{1} Q-C_{P}=P_{1} Q-\beta_{P} Q-C_{1}
$$

The income of the service department is:

$$
\pi_{S}=P Q-P_{1} Q-C_{S}=P Q-P_{1} Q-\beta_{S} Q_{1}-P_{2} Q_{2}-C_{2}
$$

Product-service integration is essentially that the product department and service department take products and services as an entire product to research and develop, design, produce and sell, standing in the perspective together to maximize the overall income of the firm to decide input, output and price, so as to achieve optimal management of the firm as a whole. Therefore, the total income function of product-service integration is expressed as:

$$
\pi_{P S}=P Q-C_{P}-C_{S}=P Q-\beta_{P} Q-\beta_{S} Q_{1}-P_{2} Q_{2}-\left(C_{1}+C_{2}\right)
$$




\section{Decision-making model analysis of product-service integration in the case of non- service outsourcing}

From assumption 6, the services are only produced by the firm's service department, so the service output is equal to the market demand, namely $Q_{1}=Q, Q_{2}=0$.

\subsection{Total income when the product department and the service department make decisions independently}

From previous assumptions, the decision-making of the product department and the service department can be seen as a two-stage non-cooperative game: on the first stage, the product department chooses $Q$ and $P_{1}$; on the second stage, the service department determines $Q$ and $P$.

Use backward induction method to solve its subgame perfect equilibrium (Benthem \& Gheerbrant, 2010):

\section{The service department determines the optimal output of products and services}

The service department sells products bundled with services to customers, in order to maximize interests of its department, it will determine the optimal output on market price $P$ and internal settlement price $P_{1}$ of the product department.

By (2):

$$
\frac{d \pi_{S}}{d Q}=\left(P-P_{1}\right)+\frac{d P}{d Q} Q-\beta_{S}=\frac{M-Q}{E}-P_{1}-\frac{Q}{E}-\beta_{S}=\frac{M}{E}-P_{1}-\beta_{S}-\frac{2 Q}{E}=0
$$

The optimal output of products and services is:

$$
Q=\frac{M-P_{1} E-\beta_{S} E}{2}
$$

Therefore, the service department orders products from the product department according to the optimal output $Q$, namely, lets the product department produce products of the quantity $Q$ for the service department by internal settlement price $P_{1}$. 
2. The product department determines the optimal internal settlement price $P_{1}$ according to the optimal output $Q$ determined by the service department

By (1) and (4):

$$
\frac{d \pi_{P}}{d P_{1}}=Q+P_{1} \frac{d Q}{d P_{1}}-\beta_{P} \frac{d Q}{d P_{1}}=\frac{M-P_{1} E-\beta_{S} E}{2}+\left(P_{1}-\beta_{P}\right) \frac{-E}{2}=\frac{M+\beta_{P} E-\beta_{S} E-2 P_{1} E}{2}=0
$$

The optimal internal settlement price is:

$$
P_{1}=\frac{M+\beta_{P} E-\beta_{S} E}{2 E}
$$

By (4) and (5), the optimal output of products and services when the product department and the service department make decisions independently is:

$$
\begin{aligned}
& Q=\frac{M-P_{1} E-\beta_{S} E}{2}=\frac{M-\frac{M+\beta_{P} E-\beta_{S} E}{2 E} E-\beta_{S} E}{2} \\
& =\frac{M-\beta_{P} E-\beta_{S} E}{4}
\end{aligned}
$$

Obviously, from the practical significance, $Q>0$, so

$$
M-\beta_{P} E-\beta_{S} E>0
$$

3. Total income when the product department and the service department make decisions independently

By (1) and (6), the income of the product department is:

$$
\pi_{P}=P_{1} Q-\beta_{P} Q-C_{1}=\left(\frac{M+\beta_{P} E-\beta_{S} E}{2 E}-\beta_{P}\right) \frac{M-\beta_{P} E-\beta_{S} E}{4}-C_{1}=\frac{\left(M-\beta_{P} E-\beta_{S} E\right)^{2}}{8 E}-C_{1}
$$

By (2) and (6), the income of the service department is:

$$
\begin{aligned}
& \pi_{S}=\left(P-P_{1}-\beta_{S}\right) Q-C_{2}=\left(\frac{M-Q}{E}-P_{1}-\beta_{S}\right) Q-C_{2} \\
& =\left(\frac{M-\frac{M-\beta_{P} E-\beta_{S} E}{4}}{E}-\frac{M+\beta_{P} E-\beta_{S} E}{2 E}-\beta_{S}\right) \frac{M-\beta_{P} E-\beta_{S} E}{4}-C_{2} \\
& =\frac{\left(M-\beta_{P} E-\beta_{S} E\right)^{2}}{16 E}-C_{2}
\end{aligned}
$$


Therefore, the total income when the product department and the service department make decisions independently is:

$$
\pi=\pi_{P}+\pi_{S}=\frac{3\left(M-\beta_{P} E-\beta_{S} E\right)^{2}}{16 E}-\left(C_{1}+C_{2}\right)
$$

\subsection{Total income when a firm makes decisions of product-service integration}

By (3):

$$
\begin{gathered}
\pi_{P S}=P Q-C_{P}-C_{S}=P Q-\left(\beta_{P}+\beta_{S}\right) Q-\left(C_{1}+C_{2}\right) \\
\frac{d \pi_{P S}}{d Q}=P+Q \frac{d P}{d Q}-\beta_{P}-\beta_{S}=\frac{M-Q}{E}-\frac{Q}{E}-\beta_{P}-\beta_{S}=\frac{M}{E}-\beta_{P}-\beta_{S}-\frac{2 Q}{E}=0
\end{gathered}
$$

The optimal output of products and services is:

$$
Q=\frac{M-\beta_{P} E-\beta_{S} E}{2}
$$

By (3) and (8), the total income when a firm makes decisions of product-service integration is:

$$
\begin{aligned}
& \pi_{P S}=P Q-\left(\beta_{P}+\beta_{S}\right) Q-\left(C_{1}+C_{2}\right)=\frac{M Q-Q^{2}}{E}-\beta_{P} Q-\beta_{S} Q- \\
& \left(C_{1}+C_{2}\right)=\frac{\left(M-\beta_{P} E-\beta_{S} E\right)^{2}}{2 E}-\frac{\left(M-\beta_{P} E-\beta_{S} E\right)^{2}}{4 E}-\left(C_{1}+C_{2}\right) \\
& =\frac{\left(M-\beta_{P} E-\beta_{S} E\right)^{2}}{4 E}-\left(C_{1}+C_{2}\right)
\end{aligned}
$$

Proposition 1: The total income when a firm makes decisions of product-service integration is larger than the total income when the product department and the service department make decisions independently, and the added value of its income $\delta \pi$ decreases as the unit price demand variation coefficient $E$ increases, decreases as the marginal cost of products $B_{P}$ increases and decreases as the marginal cost of services $B_{S}$ increases.

Proof: by (10) and (8),

$$
\begin{aligned}
& \delta \pi=\pi_{P S}-\pi=\left[\frac{\left(M-\beta_{P} E-\beta_{S} E\right)^{2}}{4 E}-\left(C_{1}+C_{2}\right)\right]-\left[\frac{3\left(M-\beta_{P} E-\beta_{S} E\right)^{2}}{16 E}-\left(C_{1}+C_{2}\right)\right] \\
& =\frac{\left(M-\beta_{P} E-\beta_{S} E\right)^{2}}{16 E}
\end{aligned}
$$


Obviously, $\delta \pi>0$, so the total income when a firm makes decisions of product-service integration is larger than the total income when the product department and the service department make decisions independently.

$$
\begin{gathered}
\frac{d \delta \pi}{d E}=\frac{-2 E\left(\beta_{P}+\beta_{S}\right)\left(M-\beta_{P} E-\beta_{S} E\right)-\left(M-\beta_{P} E-\beta_{S} E\right)^{2}}{16 E^{2}} \\
\frac{d \delta \pi}{d \beta_{P}}=\frac{2\left(M-\beta_{P} E-\beta_{S} E\right)(-E)}{16 E}=-\frac{M-\beta_{P} E-\beta_{S} E}{8} \\
\frac{d \delta \pi}{d \beta_{S}}=\frac{2\left(M-\beta_{P} E-\beta_{S} E\right)(-E)}{16 E}=-\frac{M-\beta_{P} E-\beta_{S} E}{8}
\end{gathered}
$$

By (7), $M-\beta_{P} E-\beta_{S} E>0$, so $\frac{d \delta \pi}{d E}<0, \frac{d \delta \pi}{d \beta_{P}}<0, \frac{d \delta \pi}{d \beta_{S}}<0$

Therefore, $\delta \pi$ decreases as the unit price demand variation coefficient $E$ increases, decreases as the marginal cost of products $B_{P}$ increases and decreases as the marginal cost of services $B_{S}$ increases.

\section{Decision-making model analysis of product-service integration in the case of service outsourcing}

\subsection{Total income when the product department and the service department make decisions independently in the case of service outsourcing}

According to previous assumptions, the decision-making of the product department and the service department of a firm and an outsourcing service firm can be seen as a three-stage non-cooperative game: on the first stage, the product department chooses $Q$ and $P_{1}$; on the second stage, the service department determines $Q$ and $P$; on the third stage, the outsourcing service firm determines $Q_{2}$ and $P_{2}$.

Use backward induction method to solve its subgame perfect equilibrium (Benthem \& Gheerbrant, 2010):

1. The outsourcing service firm determine the optimal supply $Q_{2}$ of services

From previous assumptions, the income of the outsourcing service firm is:

$$
\pi_{W}=P_{2} Q_{2}-C_{3}-\beta_{W} Q_{2}=\left(\beta_{S}-\beta_{W}\right) Q_{2}-Q_{2}^{2}-C_{3}
$$




$$
\frac{d \pi_{W}}{d Q_{2}}=\beta_{S}-\beta_{W}-2 \gamma Q_{2}=0
$$

The optimal supply of services of the outsourcing service firm is:

$$
Q_{2}=\frac{\beta_{S}-\beta_{W}}{2 \gamma}
$$

The optimal supply price of services of outsourcing service firm is:

$$
P_{2}=\beta_{S}-\chi_{2}=\frac{\beta_{S}+\beta_{W}}{2}
$$

Therefore, the outsourcing service firm provides services of the quantity $Q_{2}=\frac{\beta_{S}-\beta_{W}}{2 \gamma}$ for the service department of the firm by the price $P_{2}=\frac{\beta_{S}+\beta_{W}}{2}$.

\section{The service department determines the optimal output $Q$}

The service department sells products bundled with services to customers. It will determine the optimal output according to market price $P$ of products and services, internal settlement price $P_{1}$ of product department and the price $P_{2}$ of outsourcing service firm so as to maximize its interests. When the market equilibrium comes, the supply is equal to the demand, so the optimal output of products and services is equal to the market demand $Q$, therefore:

$$
\begin{aligned}
& \pi_{S}=P Q-P P_{1} Q-C_{2}-\beta_{S} Q_{1}-P_{2} Q_{2}=P Q-P_{1} Q-C_{2}-\beta_{S} Q_{1}-\left(\beta_{S}-\gamma Q_{2}\right) Q_{2} \\
& =P Q-P_{1} Q-C_{2}-\beta_{S} Q+\gamma Q_{2}^{2} \\
& \frac{d \pi_{S}}{d Q}=P+\frac{d P}{d Q} Q-P_{1}-\beta_{S}=\frac{M-Q}{E}-\frac{Q}{E}-P_{1}-\beta_{S}=\frac{M}{E}-P_{1}-\beta_{S}-\frac{2 Q}{E}=0
\end{aligned}
$$

The optimal output of products and services is:

$$
Q=\frac{M-P_{1} E-\beta_{S} E}{2}
$$

Therefore, the service department orders products from the product department according to the optimal output $Q$, namely, let the product department produce products of the quantity $Q$ for the service department by internal settlement price $P_{1}$. 
3. The product department determines the optimal internal settlement price $P_{1}$ according to the optimal output $Q$ determined by the service department

By (1) and (13):

$$
\frac{d \pi_{P}}{d P_{1}}=Q+P_{1} \frac{d Q}{d P_{1}}-\beta_{P} \frac{d Q}{d P_{1}}=\frac{M-P_{1} E-\beta_{S} E}{2}+\left(P_{1}-\beta_{P}\right) \frac{-E}{2}=\frac{M+\beta_{P} E-\beta_{S} E-2 P_{1} E}{2}=0
$$

The optimal internal settlement price of products is:

$$
P_{1}=\frac{M+\beta_{P} E-\beta_{S} E}{2 E}
$$

By (13) and (14), the optimal output of products and services when the product department and the service department make decisions independently is:

$$
\begin{aligned}
& Q=\frac{M-P_{1} E-\beta_{S} E}{2}=\frac{M-\frac{M+\beta_{P} E-\beta_{S} E}{2 E} E-\beta_{S} E}{2} \\
& =\frac{M-\beta_{P} E-\beta_{S} E}{4}
\end{aligned}
$$

4. Total income when the product department and the service department make decisions independently in the case of service outsourcing

By (1), (14) and (15), the income of the product department is:

$$
\pi_{P}=P_{1} Q-\beta_{P} Q-C_{1}=\left(\frac{M+\beta_{P} E-\beta_{S} E}{2 E}-\beta_{P}\right) \frac{M-\beta_{P} E-\beta_{S} E}{4}-C_{1}=\frac{\left(M-\beta_{P} E-\beta_{S} E\right)^{2}}{8 F}-C_{1}
$$

By (2) and (14), the income of the service department is:

$$
\begin{aligned}
& \pi_{S}=P Q-P_{1} Q-\beta_{S} Q_{1}-P_{2} Q_{2}-C_{2}=P Q-P_{1} Q-\beta_{S}\left(Q-Q_{2}\right)-P_{2} Q_{2}-C_{2} \\
& =\left(P-P_{1}-\beta_{S}\right) Q+\gamma Q_{2}^{2}-C_{2}=\left(\frac{M-Q}{E}-P_{1}-\beta_{S}\right) Q+\gamma Q_{2}^{2}-C_{2} \\
& =\left(\frac{M-\beta_{P} E-\beta_{S} E}{4}-\frac{M+\beta_{P} E-\beta_{S} E}{2 E}-\beta_{S}\right) \frac{M-\beta_{P} E-\beta_{S} E}{4}+\gamma Q_{2}^{2}-C_{2} \\
& =\frac{\left(M-\beta_{P} E-\beta_{S} E\right)^{2}}{16 E}+\frac{\left(\beta_{S}-\beta_{W}\right)^{2}}{4 \gamma}-C_{2}
\end{aligned}
$$

Therefore, the total income when the product department and the service department make decisions independently is:

$$
\pi=\pi_{P}+\pi_{S}=\frac{3\left(M-\beta_{P} E-\beta_{S} E\right)^{2}}{16 E}+\frac{\left(\beta_{S}-\beta_{W}\right)^{2}}{4 \gamma}-\left(C_{1}+C_{2}\right)
$$


4.2. Total income when a firm makes decisions of product-service integration in the case of service outsourcing

By (3):

$$
\begin{aligned}
& \pi_{P S}=P Q-\beta_{P} Q-\beta_{S} Q_{1}-P_{2} Q_{2}-\left(C_{1}+C_{2}\right)=P Q-\beta_{P} Q-\beta_{S} Q_{1}-\left(\beta_{S}-\mathcal{Q}_{2}\right) Q_{2}-\left(C_{1}+C_{2}\right) \\
& =P Q-\beta_{P} Q-\beta_{S} Q+\gamma Q_{2}^{2}-\left(C_{1}+C_{2}\right) \\
& \quad \frac{d \pi_{P S}}{d Q}=P+Q \frac{d P}{d Q}-\beta_{P}-\beta_{S}=\frac{M-Q}{E}-\frac{Q}{E}-\beta_{P}-\beta_{S}=\frac{M}{E}-\beta_{P}-\beta_{S}-\frac{2 Q}{E}=0
\end{aligned}
$$

The optimal output of products and services is:

$$
Q=\frac{M-\beta_{P} E-\beta_{S} E}{2}
$$

By (3) and (17), the total income when the product department and the service department make integration decisions is:

$$
\begin{aligned}
& \pi_{P S}=P Q-\beta_{P} Q-\beta_{S} Q+\gamma Q_{2}^{2}-\left(C_{1}+C_{2}\right)=\frac{M Q-Q^{2}}{E}-\beta_{P} Q-\beta_{S} Q \\
& +\gamma Q_{2}^{2}-\left(C_{1}+C_{2}\right)=\frac{\left(M-\beta_{P} E-\beta_{S} E\right)^{2}}{2 E}-\frac{\left(M-\beta_{P} E-\beta_{S} E\right)^{2}}{4 E}+ \\
& \frac{\left(\beta_{S}-\beta_{W}\right)^{2}}{4 \gamma}-\left(C_{1}+C_{2}\right)=\frac{\left(M-\beta_{P} E-\beta_{S} E\right)^{2}}{4 E}+\frac{\left(\beta_{S}-\beta_{W}\right)^{2}}{4 \gamma}-\left(C_{1}+C_{2}\right)
\end{aligned}
$$

Proposition 2: The total income when a firm makes decisions of product-service integration in the case of service outsourcing is larger than the total income when the product department and the service department make decisions independently.

Proof: By (18) and (16),

$$
\begin{aligned}
& \delta \pi=\pi_{P S}-\pi=\left[\frac{\left(M-\beta_{P} E-\beta_{S} E\right)^{2}}{4 E}+\frac{\left(\beta_{S}-\beta_{W}\right)^{2}}{4 \gamma}-\left(C_{1}+C_{2}\right)\right]- \\
& {\left[\frac{3\left(M-\beta_{P} E-\beta_{S} E\right)^{2}}{16 E}+\frac{\left(\beta_{S}-\beta_{W}\right)^{2}}{4 \gamma}-\left(C_{1}+C_{2}\right)\right]=\frac{\left(M-\beta_{P} E-\beta_{S} E\right)^{2}}{16 E}}
\end{aligned}
$$

Obviously, $\delta \pi>0$, so the total income when a firm makes decisions of product-service integration in the case of service outsourcing is larger than the total income when the product department and the service department make decisions independently. 
Proposition 3: Service outsourcing can improve a firm's income and the added value of the income $\delta \pi_{S}$ increases as the marginal cost of services $B_{S}$ increases, decreases as the marginal cost of outsourcing services $B_{W}$ increases, decreases as unit demand price variation coefficient of outsourcing services $\gamma$ increases.

Proof: by (18) and (10),

$$
\begin{gathered}
\delta \pi_{S}=\frac{\left(\beta_{S}-\beta_{W}\right)^{2}}{4 \gamma} \\
\frac{d \delta \pi_{S}}{d \beta_{S}}=\frac{2\left(\beta_{S}-\beta_{W}\right)}{4 \gamma}>0 \\
\frac{d \delta \pi_{S}}{d \beta_{W}}=\frac{-2\left(\beta_{S}-\beta_{W}\right)}{4 \gamma}<0 \\
\frac{d \delta \pi_{S}}{d \gamma}=\frac{-\left(\beta_{S}-\beta_{W}\right)^{2}}{4 \gamma^{2}}<0
\end{gathered}
$$

So, the added value $\delta \pi_{S}$ of the income increases as $B_{S}$ increases, decreases as $B_{W}$ increases, decreases as $\gamma$ increases.

\section{Income distribution of product-service integration}

Product-service integration improves the firm's total income. In the firm management practice, the income improvement of product-service integration is achieved because product department collaborates with service department. Therefore, only evaluate correctly each department's contribution to the added total income and take reasonable income distribution, can we ensure product-service integration is implemented successfully and is continuously effective.

\subsection{Income distribution strategy based on Shapley value method}

Cooperative game theory provides versatile and simple tools to model the generation of worth in a society and to study the "fair" or "reasonable" distribution of this worth (Casajus \& Huettner, 2014).The Shapley value is one of the most common solution concepts of cooperative game theory, which has been widely applied for solving reward/cost sharing problems in Operations Research and in economic management activities (Song \& Wei, 2013; Alparslan Gök, 2014; Zhang et al., 2014). Shapley value method is a method to allocate income according to the average contribution of cooperative game parties. The 
basic principle of income distribution based on Shapley value method is: Denote $N=\{1,2$, $\ldots, \mathrm{n}\}$ an aggregate of $\mathrm{n}$-person, $v(S)$ the income which the player subaggregate $S \subseteq N$ produces, $\phi_{i}(v), i=1,2, \ldots, n$ the Shapley value shared by player $i$ in the cooperation game $\langle v, N\rangle$ (namely, the income shared by player $i$ in the cooperation game $\langle v, N\rangle$ ). Then, the Shapley value of player $i$ can be calculated by the following formula:

$$
\phi_{\mathrm{i}}(v)=\sum_{S \in S_{i}} \frac{(n-|S|) !(|S|-1) !}{n !}[v(S)-v(S \backslash i)] \quad i=1,2, \cdots, n
$$

Where $S_{i}$ is all subaggregates containing player $i$ in the aggregate $N,|S|$ is the number of elements in the subaggregate $S, n$ is the number of elements in the aggregate $N$, $\frac{(n-|S|) !(|S|-1) !}{n !}$ represents the probability which player $i$ join in the subaggregate $S, v(S \mid i)$ is the income obtained after removing player $i$ from the subaggregate $S, v(S)-v(S \mid i) \quad$ is the added value of the income obtained after player $i$ join in the subaggregate $S$.

Based on the above analysis, product-service integration can be written as $N=\{1,2\}$, then, $S=\{1,2,1 \cup 2\}, v(1)=\pi_{P}, v(2)=\pi_{S}, v(1 \cup 2)=\pi_{P S}$. Accordingly, we can get the income shared respectively by the product department and the service department in product-service integration $\phi_{1}(v)$ and $\phi_{2}(v)$ :

$$
\begin{gathered}
\phi_{1}(v)=\frac{1 ! 0 !}{2 !}[v(1)-0]+\frac{0 ! 1 !}{2 !}[v(1 \bigcup 2)-v(2)]=\frac{1}{2} \pi_{P}+\frac{1}{2}\left(\pi_{P S}-\pi_{S}\right)=\frac{1}{2}\left(\pi_{P S}+\pi_{P}-\pi_{S}\right) \\
\phi_{2}(v)=\frac{1 ! 0 !}{2 !}[v(2)-0]+\frac{0 ! 1 !}{2 !}[v(1 \bigcup 2)-v(1)]=\frac{1}{2} \pi_{S}+\frac{1}{2}\left(\pi_{P S}-\pi_{P}\right)=\frac{1}{2}\left(\pi_{P S}+\pi_{S}-\pi_{P}\right) \\
\phi_{1}(v)+\phi_{2}(v)=\frac{1}{2}\left(\pi_{P S}+\pi_{P}-\pi_{S}\right)+\frac{1}{2}\left(\pi_{P S}+\pi_{S}-\pi_{P}\right)=\pi_{P S}
\end{gathered}
$$

Proposition 4: Income distribution of product-service integration based on Shapley value method realizes the Pareto improvement, namely $\phi_{1}(v)>\pi_{P}, \phi_{2}(v)>\pi_{S}$.

Proof: Because $\pi_{P S}>\pi_{P}+\pi_{S}$

$$
\begin{gathered}
\phi_{1}(v)-\pi_{P}=\frac{1}{2} \pi_{P}+\frac{1}{2}\left(\pi_{P S}-\pi_{S}\right)-\pi_{P}=\frac{1}{2}\left(\pi_{P S}-\pi_{P}-\pi_{S}\right)>0 \\
\phi_{2}(v)-\pi_{S}=\frac{1}{2} \pi_{S}+\frac{1}{2}\left(\pi_{P S}-\pi_{P}\right)-\pi_{S}=\frac{1}{2}\left(\pi_{P S}-\pi_{P}-\pi_{S}\right)>0
\end{gathered}
$$


Thus, $\phi_{1}(v)>\pi_{P}, \phi_{2}(v)>\pi_{S}$, namely, the income of the product department and the service department is increased, and the product department and the service department share equally the added value of income of product-service integration, so as to realize the Pareto improvement and reach a win-win situation.

\subsection{Income distribution strategy based on Equal growth rate method}

Product-service integration improves the firm's total income. Denote $\alpha$ the income growth rate, then

$$
\alpha=\frac{\pi_{P S}-\pi}{\pi}=\frac{\pi_{P S}-\pi_{P}-\pi_{S}}{\pi_{P}+\pi_{S}}
$$

Because the product department and the service department share income in the same income growth rate,

$$
\begin{gathered}
\pi_{1}=\pi_{P}(1+\alpha)=\pi_{P}\left(1+\frac{\pi_{P S}-\pi_{P}-\pi_{S}}{\pi_{P}+\pi_{S}}\right)=\frac{\pi_{P} \pi_{P S}}{\pi_{P}+\pi_{S}} \\
\pi_{2}=\pi_{S}(1+\alpha)=\pi_{S}\left(1+\frac{\pi_{P S}-\pi_{P}-\pi_{S}}{\pi_{P}+\pi_{S}}\right)=\frac{\pi_{S} \pi_{P S}}{\pi_{P}+\pi_{S}} \\
\pi_{1}+\pi_{2}=\frac{\pi_{P} \pi_{P S}}{\pi_{P}+\pi_{S}}+\frac{\pi_{S} \pi_{P S}}{\pi_{P}+\pi_{S}}=\pi_{P S}
\end{gathered}
$$

Because $\pi_{P S}>\pi_{P}+\pi_{S}$, so $\pi_{1}>\pi_{P}, \pi_{2}>\pi_{S}$, namely the income of both product department and service department increases. Therefore, we can reach the following conclusion:

Proposition 5: Income distribution of product-service integration based on Equal growth rate method realizes the Pareto improvement, namely $\pi_{1}>\pi_{P}, \pi_{2}>\pi_{S}$.

\subsection{Comparative analysis of different income distribution strategies}

1. Comparison of income distribution strategies when the product department is the main department

That product department is the main department means that product department is the main contributor to the firm's income, thus $\pi_{P}>\pi_{S}$ 


$$
\begin{aligned}
& \phi_{1}(v)-\pi_{1}=\frac{1}{2}\left(\pi_{P S}+\pi_{P}-\pi_{S}\right)-\frac{\pi_{P} \pi_{P S}}{\pi_{P}+\pi_{S}}=\frac{\left(\pi_{P S}+\pi_{P}-\pi_{S}\right)\left(\pi_{P}+\pi_{S}\right)-2 \pi_{P} \pi_{P S}}{2\left(\pi_{P}+\pi_{S}\right)} \\
& =\frac{\left(\pi_{P S}-\pi_{P}-\pi_{S}\right)\left(\pi_{S}-\pi_{P}\right)}{2\left(\pi_{P}+\pi_{S}\right)} \\
& \phi_{2}(v)-\pi_{2}=\frac{1}{2}\left(\pi_{P S}+\pi_{S}-\pi_{P}\right)-\frac{\pi_{S} \pi_{P S}}{\pi_{P}+\pi_{S}}=\frac{\left(\pi_{P S}+\pi_{S}-\pi_{P}\right)\left(\pi_{P}+\pi_{S}\right)-2 \pi_{S} \pi_{P S}}{2\left(\pi_{P}+\pi_{S}\right)} \\
& =\frac{\left(\pi_{P S}-\pi_{P}-\pi_{S}\right)\left(\pi_{P}-\pi_{S}\right)}{2\left(\pi_{P}+\pi_{S}\right)}
\end{aligned}
$$

Because $\pi_{P}>\pi_{S}, \pi_{P S}>\pi_{P}+\pi_{S}$, so

$\phi_{1}(v)-\pi_{1}<0, \phi_{1}(v)<\pi_{1}$, income distribution of product-service integration based on Equal growth rate is beneficial to product department.

$\phi_{2}(v)-\pi_{2}>0, \phi_{2}(v)>\pi_{2}$, income distribution of product-service integration based on Shapley value is beneficial to service department.

Modern business management has become a market-centered management model. Because service department is directly facing the market, the service department has priority over selection of income distribution strategies. Accordingly, the service department will choose income distribution of product-service integration based on Shapley value method so as to maximize the income of its department. Therefore, we can reach the conclusion as follows:

Proposition 6: When product department is the main contributor to a firm's income, the service department will choose income distribution of product-service integration based on Shapley value method so as to maximize the income of its department.

2. Comparison of income distribution strategies when the service department is the main department

The service department is the main department means that the service department is the main contributor to a firm's income, so $\pi_{S}>\pi_{P}$

$$
\begin{aligned}
& \phi_{1}(v)-\pi_{1}=\frac{1}{2}\left(\pi_{P S}+\pi_{P}-\pi_{S}\right)-\frac{\pi_{P} \pi_{P S}}{\pi_{P}+\pi_{S}}=\frac{\left(\pi_{P S}+\pi_{P}-\pi_{S}\right)\left(\pi_{P}+\pi_{S}\right)-2 \pi_{P} \pi_{P S}}{2\left(\pi_{P}+\pi_{S}\right)} \\
& =\frac{\left(\pi_{P S}-\pi_{P}-\pi_{S}\right)\left(\pi_{S}-\pi_{P}\right)}{2\left(\pi_{P}+\pi_{S}\right)}
\end{aligned}
$$




$$
\begin{aligned}
& \phi_{2}(v)-\pi_{2}=\frac{1}{2}\left(\pi_{P S}+\pi_{S}-\pi_{P}\right)-\frac{\pi_{S} \pi_{P S}}{\pi_{P}+\pi_{S}}=\frac{\left(\pi_{P S}+\pi_{S}-\pi_{P}\right)\left(\pi_{P}+\pi_{S}\right)-2 \pi_{S} \pi_{P S}}{2\left(\pi_{P}+\pi_{S}\right)} \\
& =\frac{\left(\pi_{P S}-\pi_{P}-\pi_{S}\right)\left(\pi_{P}-\pi_{S}\right)}{2\left(\pi_{P}+\pi_{S}\right)}
\end{aligned}
$$

Because $\pi_{S}>\pi_{P}, \pi_{P S}>\pi_{P}+\pi_{S}$, so

$\phi_{1}(v)-\pi_{1}>0, \phi_{1}(v)>\pi_{1}$, income distribution of product-service integration based on Shapley value method is beneficial to the product department.

$\phi_{2}(v)-\pi_{2}<0, \phi_{2}(v)<\pi_{2}$, income distribution of product-service integration based on Equal growth rate method is beneficial to service department.

Because the service department is the main department and the service department is directly facing the market, the service department dominates the selection of income distribution strategies. Thus, the service department will choose income distribution of product-service integration based on Equal growth rate method so as to maximize the income of its department. Therefore, we can reach the following conclusion:

Proposition 7: When the service department is the main contributor to firm income, the service department will choose income distribution of product-service integration based on Equal growth rate method so as to maximize the income of its department.

\section{Conclusions}

This paper firstly adopts game theory to study the coordination mechanism of product-service integration. Results show that product-service integration increases the total income of a firm and the added value of the income $\delta \pi$ decreases as the unit price demand variation coefficient of products and services $\mathrm{E}$ increases, decreases as the marginal cost of products $B_{P}$ increases, decreases as the marginal cost of services $B_{S}$ increases.

The study also demonstrates that service outsourcing can improve a firm's income and the added value of its income $\delta \pi_{S}$ increases as the marginal cost of services $B_{S}$ increases, decreases as the marginal cost of outsourcing services $B_{W}$ increases, and decreases as the unit price demand variation coefficient of outsourcing services $\gamma$ increases.

In addition, the paper also makes an in-depth study on income distribution strategies of product-service integration. Findings suggest that both income distribution strategies of product-service integration based on Shapley value method and Equal growth rate method can 
realize the Pareto improvement and reach a win-win situation. The choice of what kind of distribution strategy to coordinate the actions between departments depends on the department playing dominant role in the firm. Generally speaking, when product department is the main contributor to firm income, the service department will choose income distribution strategy of product-service integration based on Shapley value method so as to maximize interests of its department; when the service department is the main contributor to firm income, the service department will choose the income distribution strategy of product-service integration based on Equal growth rate method so as to maximize interests of its department.

In order to facilitate the analysis, this paper makes some strict assumptions, which provides opportunity for future researches on relaxing the assumption, in-depth study of complex relationship between products and services and so on.

\section{Acknowledgements}

This paper is supported by the Natural Science Foundation of China (Grant No. 71240023), Humanities and Social Science Research Project of the Ministry of Education of China (Grant No. 12YJA630198). 


\section{References}

Alparslan Gök, S.Z. (2014). On the interval Shapley value. Optimization. 63(5), 747-755. http://dx.doi.org/10.1080/02331934.2012.686999

Baines, T.S., Lightfoot, H.W., Benedettini, O., \& Kay, J.M. (2009). The servitization of manufacturing: A review of literature and reflection on future challenges. Journal of Manufacturing Technology Management, 20(5), 547-567.

http://dx.doi.org/10.1108/17410380910960984

Benthem, J. van, \& Gheerbrant, A . (2010). Game Solution, Epistemic Dynamics and Fixed-Point Logics. Fundamenta Informaticae, 100, 19-41.

Casajus, A., \& Huettner, F. (2014). Null, nullifying, or dummifying players: The difference between the Shapley value, the equal division value, and the equal surplus division value. Economics Letters, 122, 167-169. http://dx.doi.org/10.1016/j.econlet.2013.11.008

Dachs, B., Biege, S., Borowiecki, M., Lay, G., Jäger, A., \& Schartinger, D. (2014). Servitisation of European manufacturing: Evidence from a large scale database. Service Industries Journal, 34(1), 5-23. http://dx.doi.org/10.1080/02642069.2013.776543

Geum, Y., Lee, S., Kang, D., \& Park, Y. (2011a). The customisation framework for roadmapping product-service integration. Serv Bus, 5, 213-236. http://dx.doi.org/10.1007/s11628-011-0111-0

Geum, Y., Lee, S., Kang, D., \& Park, Y. (2011b). Technology roadmapping for technology-based product-service integration: A case study. Journal of Engineering and Technology Management, 28, 128-146. http://dx.doi.org/10.1016/j.jengtecman.2011.03.002

Han, S., Kuruzovich, J., \& Ravichandran, T. (2013). Service Expansion of Product Firms in the Information Technology Industry: An Empirical Study. Journal of Management Information Systems, 29(4), 127-158. http://dx.doi.org/10.2753/MIS0742-1222290405

Johnstone, S. \& Dainty, A., \& Wilkinson, A. (2009). Integrating products and services through life: An aerospace experience. International Journal of Operations \& Production Management, 29(5), 520-538. http://dx.doi.org/10.1108/01443570910953612

Mathieu, V. (2001). Product services: From a service supporting the product to a service supporting the client. The Journal of Business \& Industrial Marketing, 16 (1), 39-61. http://dx.doi.org/10.1108/08858620110364873

Parida, V., Sjödin, D.R., Wincent, J., \& Kohtamäki, M. (2014). Mastering the Transition to Product-Service Provision. Research-Technology Management, 57(3), 44-52. 
Park, Y., Geuma, Y., \& Lee, H. (2012). Toward integration of products and services: Taxonomy and typology. Journal of Engineering and Technology Management, 29, 528-545. http://dx.doi.org/10.1016/j.jengtecman.2012.08.002

Pindyck, R.S., \& Rubinfeld, D.L. (2013). Microeconomics (Eighth Edition). Beijing: China Renmin University Press.(In Chinese).

Song, Y., \& Wei, J. (2013). A Comparative Analysis of the Strategic Investor and the Financial Investor Based on the Shapley Value of Cooperative Game. Mathematics in Practice and Theory, 43(23), 74-79.(In Chinese).

Sundin, E., Lindahl, M., Rönnbäck, A.O., Ölundh, G., Östlin, J. (2006). Integrated product and service engineering methodology. In: Proceedings of 11th International Conference of Sustainable Innovation, Chicago.

Vandermerwe, S., \& Rada, J. (1988). Servitization of business: Adding value by adding services. European Management Journal, 6 (4), 314-324. http://dx.doi.org/10.1016/02632373(88)90033-3

Zhang, H., Xu, R., \& Zhang, X. (2014). Decision model for drinking water facilities cost under cooperative game. Systems Engineering, 32(2), 98-102. (In Chinese).

http://dx.doi.org/10.1016/0263-2373(88)90033-3

Journal of Industrial Engineering and Management, 2014 (www.jiem.org)

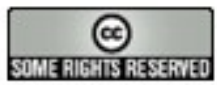

Article's contents are provided on a Attribution-Non Commercial 3.0 Creative commons license. Readers are allowed to copy, distribute and communicate article's contents, provided the author's and Journal of Industrial Engineering and Management's names are included. It must not be used for commercial purposes. To see the complete license contents, please visit http://creativecommons.org/licenses/by-nc/3.0/. 